\title{
Caste formation in larval Himasthla elongata (Trematoda) infecting common periwinkles Littorina littorea
}

\author{
SIGRID S. NIELSEN, MALAN JOHANSEN AND KIM N. MOURITSEN \\ Department of Bioscience, Aarhus University, Ole Worms Allé 1, 80oo Aarhus C, Denmark
}

\begin{abstract}
Reproductive division of labour is well-known in several animal groups but the ecological factors driving the evolution of such social organization are still being discussed. Recent studies have discovered social organization in four marine species of trematode parasites having two distinct castes specialized for reproduction and defence of the clonal intra-molluscan larval colony, respectively. Here, we provide novel evidence for social structure also in colonies of the trematode Himasthla elongata infecting the common periwinkle Littorina littorea. We found two types of rediae, the parthenogenetic larval offspring of the parasite: small non-reproductive rediae and considerably larger reproductive rediae. Both redial types possessed a digestive system, collar and posterior appendages and, hence, aside from dimensions, were morphologically similar. However, in vitro experiments showed that non-reproductive morphs attacked heterospecific competing parasites at a higher rate (2-3 fold) than reproductive morphs did. No within-colony antagonism was observed. In contrast to a previous study on a congeneric trematode species, our findings suggest a relatively weak caste formation in $\mathrm{H}$. elongata, possibly resulting from a corresponding weaker level of interspecific competition.
\end{abstract}

Keywords: altruism, Himasthla elongata, division of labour, Littorina littorea, parasite-parasite antagonism, redia

Submitted 5 June 2013; accepted 29 January 2014; first published online 2 April 2014

\section{INTRDDUCTION}

The evolution of non-reproductive and reproductive castes, primarily known from social insects (e.g. Wilson, 1971; Crespi \& Yanega, 1995), has been a vigorous research area since Darwin's time, because natural selection is a process based on reproductive success. It is, therefore, difficult to explain how altruistic non-reproductive individuals can evolve (see e.g. Nowak et al., 2010; Abbot et al., 2011). So far the most successful and recognized theory explaining the evolution of non-reproductive castes is Hamilton's kin selection theory based on the concept of inclusive fitness (Bourke, 2011), though there have been challenges to this theory recently (e.g. Nowak et al., 2010). It states that there can be selection for altruistic behaviour if such behaviour results in a higher inclusive fitness than direct fitness for the altruistic individual (Hamilton, 1964). To make this possible, relatedness between individuals is required, but high relatedness cannot drive the evolution of altruism by itself (Hughes et al., 2008). Certain ecological factors, such as presence of a spatially well-defined and delimited food resource to defend, and strong inter- or intraspecific competition over that resource (selection for defence), also appear necessary for the evolution of altruism (Crespi, 1994). However, it can be difficult to determine which ecological factors are important since the relatedness between individuals is not the same within all taxa where nonreproductive and reproductive castes have evolved.

Corresponding author:

K.N. Mouritsen

Email: kim.mouritsen@biology.au.dk
The influence of ecological factors can be evaluated by contrasting colonies of different social species with similar degree of relatedness between individuals, as any differences in the social structure can therefore be ascribed to present or past ecological conditions, all else being equal. Parasitic trematodes could be such a study system, as evidences for formation of non-reproductive and reproductive castes were recently found in the larval stages of a marine echinostome trematode species (Himasthla sp. B) infecting the California horn snail, Cerithidea californica (Haldeman, 1840) (Hechinger et al., 2011), as well as in other trematode species (Miura, 2012; Leung \& Poulin, 2012). The two identified castes differ both morphologically and behaviourally in that one caste is specialized in defending the colony against other competing parasites that might invade the host organism, whereas the other caste is engaged predominantly in reproduction by producing dispersal stages that leave the host to find the next host in the parasite's life cycle.

Echinostome trematodes (Echinostomatidae) often have a three-host life cycle involving a gastropod first intermediate host, a bivalve second intermediate host and a water bird as definitive host (Lauckner, 1980, 1983; Galaktionov \& Dobrovolskij, 2003; Esteban \& Muñoz-Antoli, 2009). The parasites reproduce sexually in the intestine of the bird from which eggs are expelled to the surrounding environment via the host's faeces. The trematode egg then hatches into a miracidium larva that seeks out and penetrates the first intermediate host, in which it reproduces asexually into a colony of rediae that eventually infest most of the visceral mass of the host. The echinostome redia is equipped with a mouth, a pharynx and a gut, and it literally eats its way through the host tissues. Upon maturity, the redia produces either a new 
redial generation or the parasite's dispersal stage (cercariae); the latter leave the snail host in order to invade the next host in the life cycle. Here, the cercariae encyst as dormant metacercariae and await trophic transmission to the definitive avian host preying on the second intermediate host.

The intra-molluscan trematode larvae are particularly useful for the study of social organization in an ecological context because they form clonal colonies without genetic conflicts between individuals: the relatedness is the same in all colonies. In this respect trematodes resemble, for instance, the eusocial gall-forming aphids (Aoki, 1977). Furthermore, the redial stages are equipped with a feeding apparatus that allows for antagonistic behaviour and thus retain the ability to compete over the common limited resource (the host). Finally, the larvae of different species of trematodes live under different ecological conditions, such as resource availability in terms of size, abundance and longevity of their molluscan host, and/or the level of inter- and intraspecific competition, which differs according to host species and shows great spatio-temporal variation (Sousa, 1983; Kuris \& Lafferty, 1994; Poulin \& Mouritsen, 2003).

Hechinger et al. (2011) suggest three ecological factors that will make the evolution of a specialized soldier caste in trematode species more likely. First, the trematode species has to be dominant in the interspecific hierarchy since this indicates the ability to effectively defend itself. Second, the infection incidence in the host population has to be high, as this increases the probability of multiple infections and hence inter- or intraspecific competition. Third, the host has to have a long lifespan, since this will increase the probability of interactions between different species within the host and make the possible returns from future reproduction higher. These ecological factors differ between trematode species, and we therefore investigated the social structure of the marine trematode Himasthla elongata (Mehlis, 1831) that infects the common periwinkle Littorina littorea (L.). Compared to the congeneric Himasthla sp. B studied by Hechinger et al. (2011), H. elongata may be less dominant in the interspecific hierarchy (see Werding, 1969; Lauckner, 1980). Moreover, the overall infection incidence by trematodes is lower in L. littorea populations (less competitive pressure) than in Cerithidea californica populations hosting Himasthla sp. B (Poulin \& Mouritsen, 2003). We therefore hypothesized the redial stage of $H$. elongata to be less specialized for defence of the colony than Himasthla sp. B. Based on the findings by Hechinger et al. (2011) we conducted a series of studies on $H$. elongata rediae in order to examine three questions:

- Do the non-reproductive and reproductive rediae differ in size and morphology?

- Is the distribution of non-reproductive and reproductive rediae the same in different parts of the host snail?

- Do the non-reproductive and reproductive rediae differ in their willingness to attack other trematode species?

\section{MATERIALS AND METHODS}

\section{Collections of animals}

Periwinkles, Littorina littorea, were collected from two sites: (1) on a pier at the northern part of Aarhus harbour, Denmark, in April 2011; and (2) in Knebel vig, a small bay $8 \mathrm{~km}$ north-east of Aarhus harbour, in October 2013. Here, the periwinkles are known to host colonies of Himasthla elongata rediae as well as other trematode species-particularly Renicola roscovita, but also Cryptocotyle lingua. The snails were maintained in the laboratory in seawater at $5^{\circ} \mathrm{C}$ for maximum $2 \mathrm{wk}$ prior to dissection.

\section{Dimensions, morphology and within-host distribution of rediae}

The shell height of each snail was measured (apex to aperture), after which the shell was cracked with pliers and the snails' soft tissue carefully removed. The anterior visceral mass of each snail was removed by cutting through the albumen gland, and the retained softer mainly gonad/digestive gland complex was divided in two evenly-sized parts by cutting just posterior to the kidney. These two body parts (hereafter denoted the front and hind part) were moved to separate Petri dishes and further dissected for presence of $H$. elongata rediae. The mantle of snails collected at the second site (Knebel vig) was also inspected under a light microscope for enumeration of present rediae. Dissecting the different body parts separately was done because Hechinger et al. (2011) found reproductive and non-reproductive rediae of Himasthla sp. B to be unevenly distributed within the host body. If present, rediae from the front and hind part were isolated by removing as much snail tissue as possible followed by rinsing in filtered $(10 \mu \mathrm{m})$ seawater. To avoid severe contraction of larvae often seen during chemical preservation, the parasites were killed by letting them dry out in the dish and then rehydrated to their original size. With a pipette we isolated a subsample of larval parasites both from the front and the hind part of each Himasthla-infected snail by sucking them up haphazardly according to type and size and shape. Under a stereomicroscope equipped with an ocular micrometer, we measured the length and width of each redia at $40 \times$ magnification. The redial width was measured at two different sites on the animal: one measure was taken $\sim_{1} / 4$ body length posterior to the front, the other was taken $\sim 1 / 4$ body length anterior to the hind part. These two measures were then averaged to obtain a single width value for further analysis. The volume of the redia was calculated by approximating the shape of the redia to a cylinder. Each redia was classified as reproductive or non-reproductive based on the occurrence/ absence of germinal masses or cercariae at different developmental stages within their body. In case of doubt, rediae were examined under a light microscope at $100 \times$ magnification. Also, it was noted whether the rediae possessed collars and posterior locomotor appendages often characterizing rediae of the genus Himasthla (e.g. Stunkard, 1938, 1966). In this way we processed in total 2922 rediae; 1304 from the front part and 1618 from the hind part of ten infected snails (five from each site) measuring between 21.1 and $26.9 \mathrm{~mm}$ in shell height. The 412 rediae found in the snails mantles were not measured and solely inspected under the light microscope. If not otherwise stated, these individuals are, therefore, excluded in given numbers of processed rediae.

\section{Attack frequencies of reproductive and non-reproductive rediae}

In a controlled experiment we tested whether reproductive and non-reproductive $H$. elongata rediae originating from 
the same colony attack sporocysts of the heterospecific trematode Renicola roscovita (Stunkard, 1932) with similar frequency. Renicola sporocysts were obtained from the same population of periwinkles as the applied $H$. elongata rediae (Aarhus harbour), and they were isolated in the same way as $H$. elongata. We made two treatments with different combinations of $H$. elongata and $R$. roscovita and one control treatment. In the first treatment, we combined 20 nonreproductive $H$. elongata rediae with $20 R$. roscovita sporocysts $(\mathrm{N}=10)$. In a second treatment, we combined 20 reproductive $H$. elongata rediae with $20 R$. roscovita sporocysts $(\mathrm{N}=10)$. In the control treatment we combined 20 reproductive and 20 non-reproductive $H$. elongata rediae from the same colony $(\mathrm{N}=9)$. The replicates in each of these treatments included $H$. elongata rediae from separate colonies/snails, whereas rediae across treatments within given replicates originated from the same colony (paired design). The experiment was performed at room temperature $\left(22.5-25^{\circ} \mathrm{C}\right)$ in concave glass wells with $0.75 \mathrm{ml}$ filtered $(10 \mu \mathrm{m})$ seawater. To avoid a possible higher activity of nonreproductive rediae affecting observed attack rates (see Hechinger et al., 2011), we ensured that all parasite larvae were in close proximity to each other at onset of the experiment. During the experiment, we recorded the number of attacks by respectively reproductive and non-reproductive $H$. elongata rediae under a stereomicroscope for 1 min after $10,30,60,90$ and $120 \mathrm{~min}$ from the beginning of the experiment. The maximum number of attacks observed in each replicate during the $2 \mathrm{~h}$ experimental period was used for further analyses. An attack was defined as when a redia had its mouthparts latched onto another trematode larva.

\section{RESULTS}

\section{Dimensions, morphology and within-host distribution of rediae}

Of the 732 Himasthla elongata rediae processed from the first site (Aarhus harbour), 158 were non-reproductive and 574

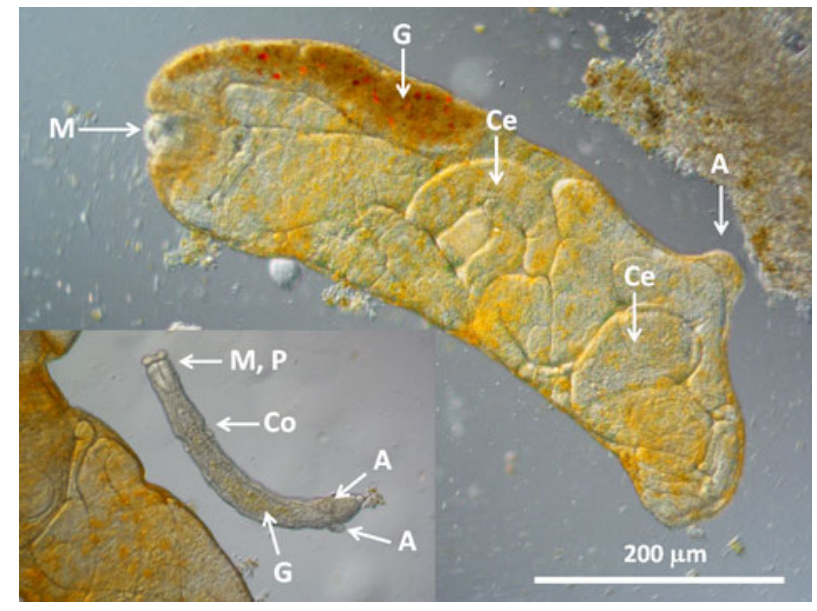

Fig. 1. Reproductive Himasthla elongata redia containing developing cercariae. Insert: non-reproductive $H$. elongata redia next to a section of the distinctively larger reproductive rediae. Arrows denote mouth $(\mathrm{M})$, pharynx $(\mathrm{P})$, collar $(\mathrm{Co})$, gut $(\mathrm{G})$, maturing cercariae contained within the redia body $(\mathrm{Ce})$, posterior locomotor appendage (A). Note that collar is not visible on the partly contracted reproductive redia, but is so on more elongated individuals. Light microscopy using differential interference contrast.

were reproductive. Of the 2190 rediae processed from the second site (Knebel vig), 304 were non-reproductive and 1886 were reproductive. Non-reproductive rediae were generally smaller and had a relatively narrower body than reproductive rediae and, hence, had a markedly smaller volume (Figures 1-3). The mean length-to-width ratio across the five studied colonies from Aarhus harbour was 4.9 for nonreproductive rediae and 3.4 for reproductive rediae. There was, however, a considerable overlap in individual dimensions between the two redial types within all five colonies (Figures $2 \mathrm{~A}$ and $3 \mathrm{~A}$ ). This was particularly pronounced in colony 4 , and to some extent also in colony 2 , which contained some very large non-reproductive rediae (Figure $2 \mathrm{~A}$ ). The mean length-to-width ratio of rediae from Knebel vig was 6.1 for non-reproductive rediae and 4.0 for reproductive rediae, and no overlap in individual dimensions between the two redial types was seen at this site (Figures $2 \mathrm{~B}$ and $3 \mathrm{~B}$ ).
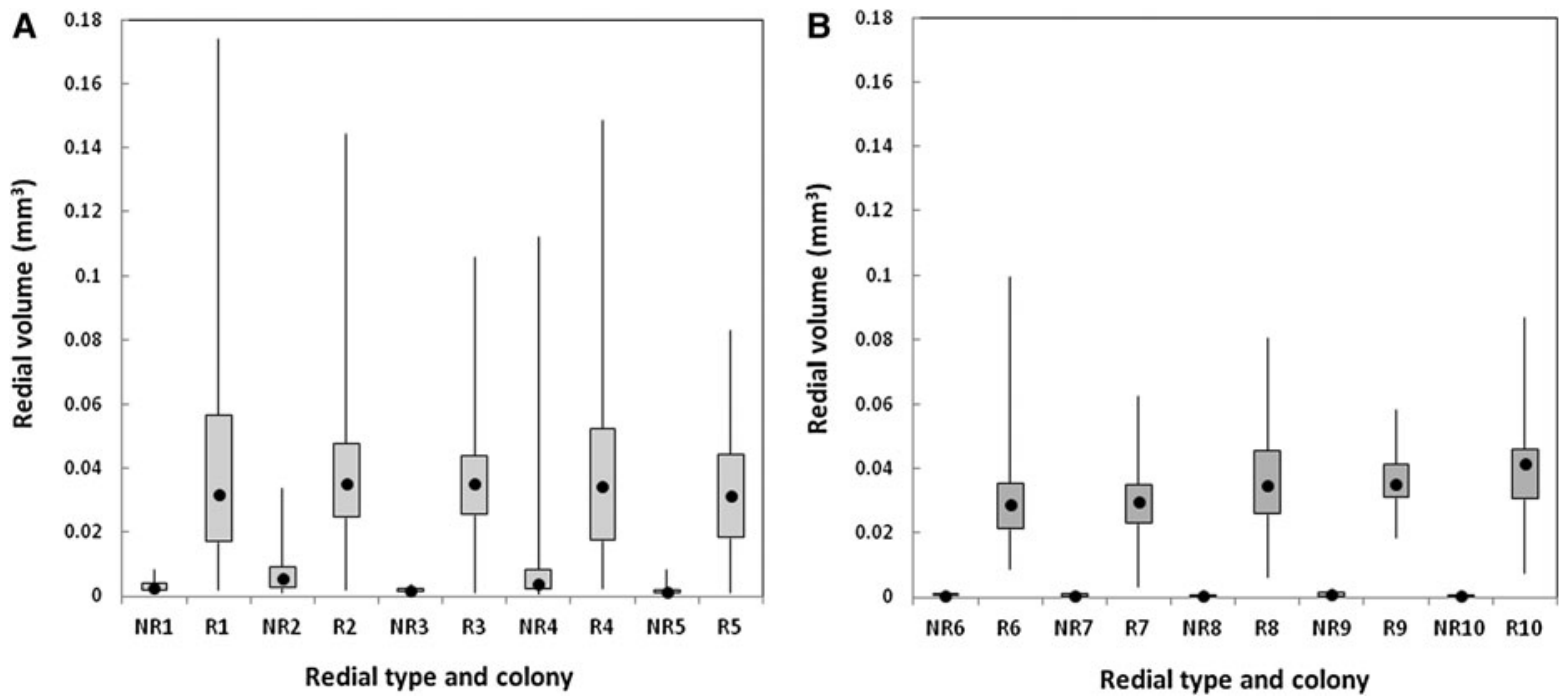

Fig. 2. Volume box-plot (maximum, minimum, $25 \%$ and $75 \%$ quartile, and median [ $\bullet$ ]) of Himasthla elongata rediae from (A) the five colonies from Aarhus harbour; (1-5: separate colonies (snails); redial sample sizes from left to right are: 14, 83, 11, 66, 16, 71, 87, 248, 30 and 105) and (B) the five colonies from Knebel (6-10: separate colonies; redial sample sizes from left to right: $21,80,23,73,17,70,20,82,20$ and 86 ) . NR, non-reproductive rediae; R, reproductive rediae. 

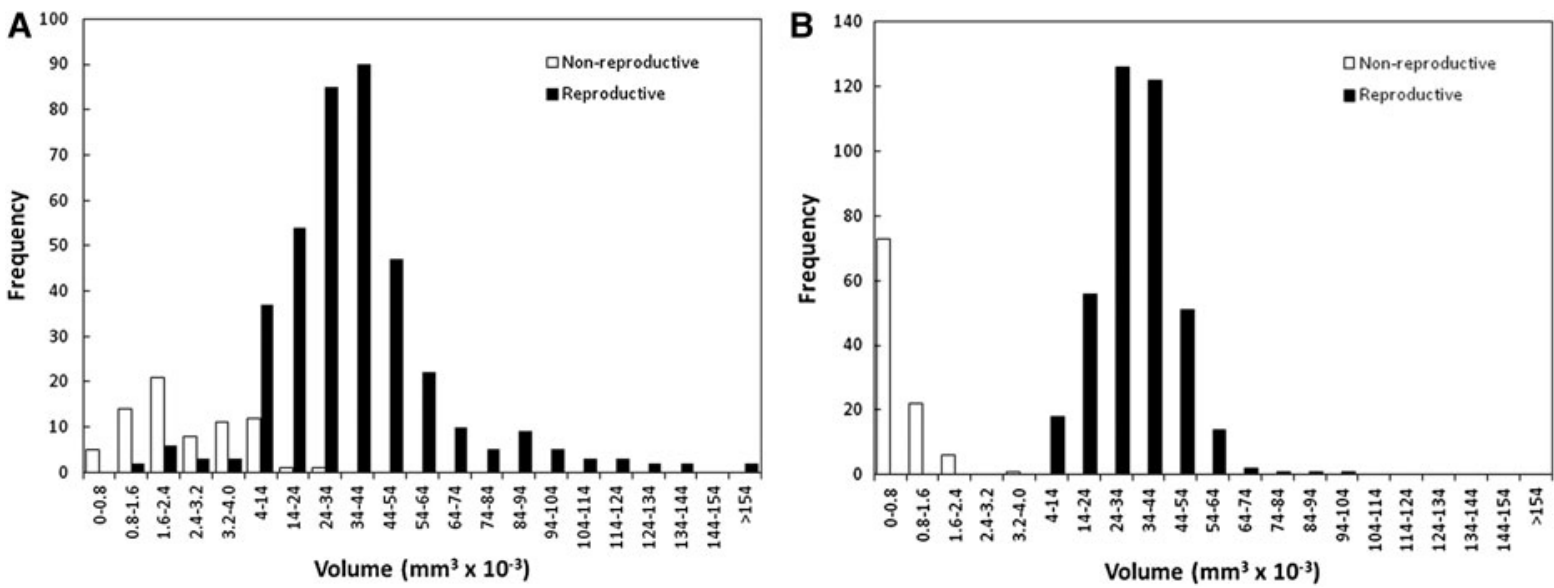

Fig. 3. Frequency distribution of redial volume of Himasthla elongata for (A) all Aarhus colonies combined and (B) all Knebel colonies combined. Note that frequencies of non-reproductive and reproductive rediae do not reflect actual relative proportion of the two redial morphs in the colonies. The included numbers of respectively non-reproductive and reproductive were standardized across colonies in order to obtain approximately similar weight by colony (Aarhus: 11-16 non-reproductive and 66-84 reproductive rediae per colony; Knebel: 17-23 non-reproductive and 70-86 reproductive rediae per colony). Also note that size-classes differ.

Aside from the non-reproductive's larger sucker, pharynx and stomach relative to body size, there were no clear differences in the morphological structures between nonreproductive and reproductive rediae from either site. Both redial types possessed well-defined collar and posterior locomotor appendages, albeit these structures were less pronounced in the often swollen reproductive morphs (Figure 1).

Average redial width and length was unaffected by the position of the rediae in the gonad/digestive gland complex (front versus hind part), irrespective of whether they were nonreproductive (paired samples $t$-test, $t_{4} \leq 0.651, P \geq 0.550$ ) or reproductive (paired samples $t$-test, $t_{4} \leq 1.943, P \geq 0.124$ ). This allowed us to combine size data from the hind and front part of the five snails from each site in two separate analysis, which showed a statistically significant difference between reproductive and non-reproductive rediae at either sites both regarding mean body width $\left(t_{4} \geq 10.440, P<\right.$ $0.0005)$, mean body length $\left(t_{4} \geq 3.552, P=0.007\right)$ and therefore also mean body volume $\left(t_{4} \geq 13.835, P<0.0005\right)$ (Figures 2 and 3 ). Across site, there was no significant difference in average volume of reproductive rediae (Student's $t$-test, $t_{8}=0.226, P=0.827$ ), whereas non-reproductive rediae were significantly larger at the Aarhus site than at Knebel vig $\left(t_{8}=\right.$ 3.129, $P=0.014$ ) (Figures 2 and 3 ). Also, the variation in volume was somewhat larger for both non-reproductive and reproductive rediae at Aarhus than at Knebel.

At the Aarhus site, the reproductive rediae occurred approximately four times more frequently than nonreproductive $(74.1-85.7 \%$ reproductive across colonies; one-sample $t$-test, $t_{4}=13.433, P<0.0005$ ), and the relative proportion of non-reproductive rediae did not differ between the front part (mean percentage \pm standard error: $19.6 \pm 2.7)$ and the hind part $(18.8 \pm 3.8)$ of the hosts gonad/digestive gland (paired samples $t$-test, $t_{4}=0.338, P=$ $0.753)$. At Knebel vig, reproductive rediae were also more frequent ( $\sim$ six-fold) than non-reproductive (76.7-91.1\%; onesample $t$-test, $\left.t_{4}=14.260, P<0.0005\right)$, and neither was there any difference in the relative proportion of redial types between the front $(15.9 \pm 3.9 \%$ non-reproductive $)$ and the hind part (11.4 $\pm 1.8 \%$ non-reproductive) of the snail hosts (paired samples $t$-test, $t_{4}=1.661, P=0.172$ ). The relative proportion of redial types did not differ significantly between sites (Student's $t$-test, $t_{8}=1.689, P=0.130$ ). The mantles of snails from Knebel vig were also screened for rediae, and in this part of the host, the proportion of nonreproductive rediae was considerably higher $(57.8 \pm 4.8 \%)$ than in the other two parts combined $(13.2 \pm 2.6 \%$; paired samples $t$-test, $\left.t_{4}=9.192, P=0.001\right)$. A one-way ANOVA contrasting all three body parts in one analysis, but not correcting for inter-colony variation, reached similar conclusions $\left(\mathrm{F}_{2,12}=48.504, P<0.0005\right.$; Bonferroni post hoc tests, front vs hind part: $P=1.000$, front and hind part vs mantle: $P<$ $0.0005)$. Although we did not record presence of dead or dying rediae systematically, it was noted that quite a lot of reproductive specimens in the mantle region appeared to be dead (these were excluded in the analyses).

\section{Attack frequencies of reproductive and non-reproductive rediae}

Himasthla elongata rediae readily attacked heterospecific trematode larvae (here $R$. roscovita sporocysts) (Figures 4 and 5). A paired samples $t$-test, which took possible differences between individual colonies into account, showed that the non-reproductive $H$. elongata rediae attacked $R$. roscovita sporocysts $2-3$ times more frequently than the reproductive rediae did $\left(t_{9}=3.478, P=0.007\right.$; Figure 5$)$. Furthermore, both non-reproductive rediae (paired samples $t$-test, $t_{8}=$ 4.800, $P=0.001$ ) and reproductive rediae (paired samples $t$-test, $t_{8}=2.485, P=0.038$ ) attacked $R$. roscovita sporocysts significantly more often than conspecifics from their own colony that were never attacked (Figure 5).

\section{DISCUSSIDN}

Present results demonstrate that the clonal redial stages of Himasthla elongata form two relatively distinct groups: one comprised small and narrow non-reproductive rediae possessing relatively greater willingness to attack heterospecific trematodes, and another comprised relatively large and 


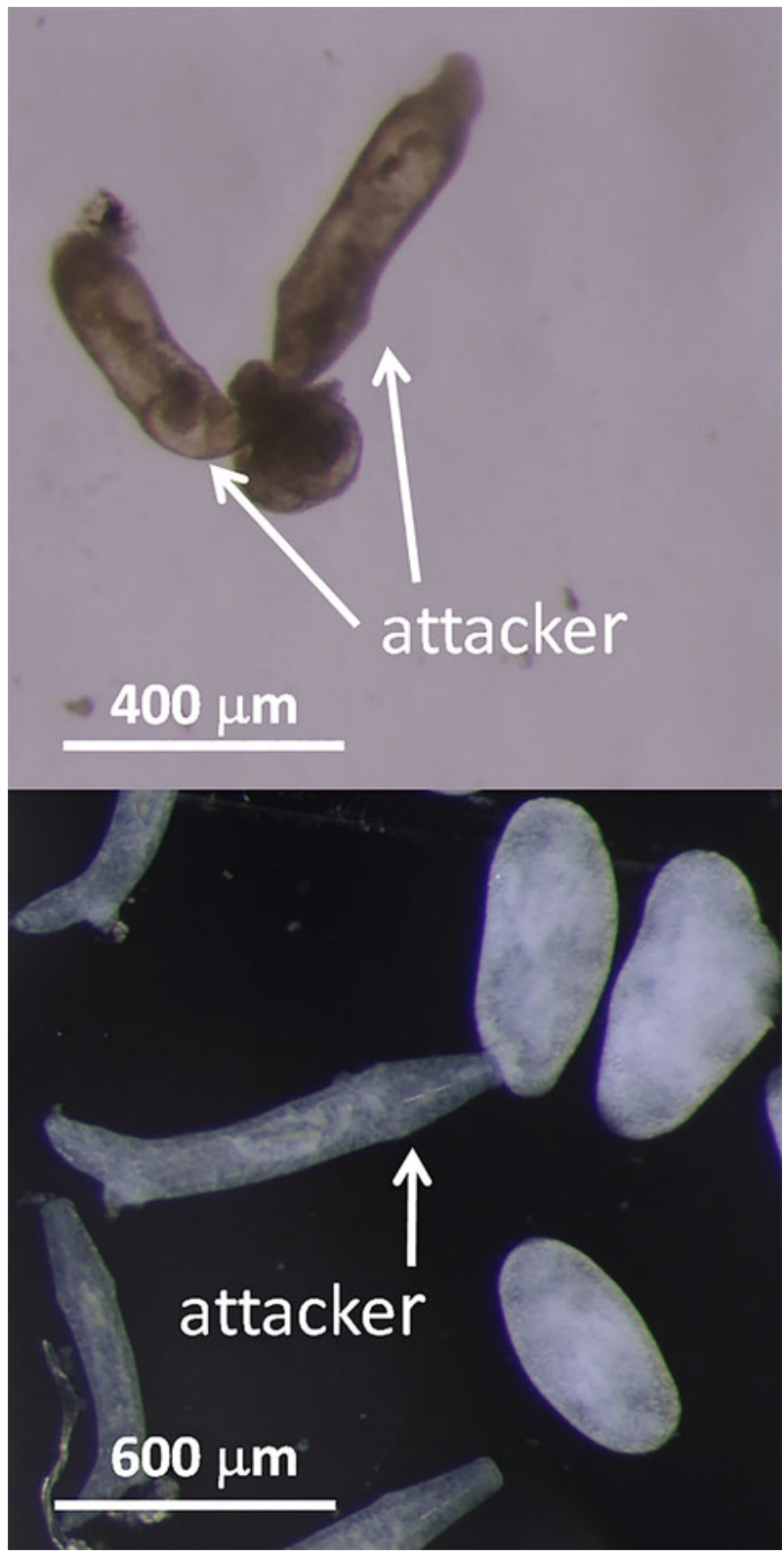

Fig. 4. Non-reproductive Himasthla elongata rediae attacking Renicola roscovita sporocysts (stereomicroscopy).

broad reproductive rediae less willing to engage in heterospecific attacks. This suggests that division of labour under its widest definition (see e.g. Wilson, 1971; Crespi \& Yanga, 1995) has evolved in $H$. elongata or its ancestor, in which the clonal colony of rediae is divided into two main castes, a 'soldier' caste specialized for defence and a caste specialized for reproduction. Hence, our investigation is in accordance with Hechinger et al. (2011), Leung \& Poulin (2012) and Miura (2012), who found comparable evidence also in the trematodes Himasthla sp. B, Philopthalmus sp., and Philophthalmid sp. I, Philophthalmid sp. II and Acanthoparyhium sp. I, respectively. Our study represents the first demonstration of division of labour in a species of trematode from the European continent, and the first social trematode whose entire life cycle has previously been thoroughly described.

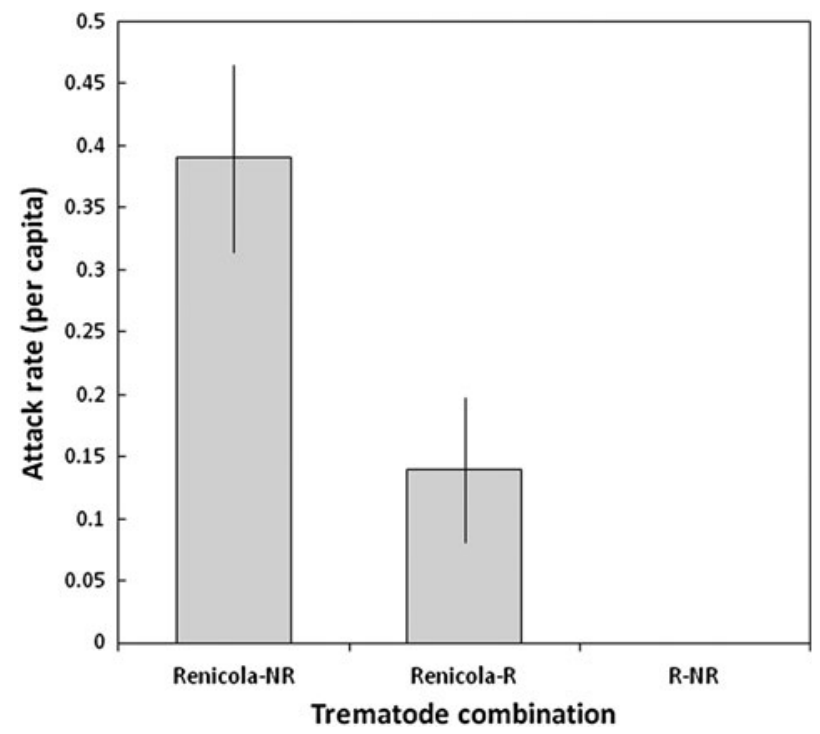

Fig. 5. Attack rates (mean number of attacks per capita \pm standard error, $\mathrm{N}=10$ ) of non-reproductive (NR) and reproductive (R) Himasthla elongata rediae on Renicola roscovita sporocysts (Renicola) and conspecifics (reproductive rediae from same colony).

Contrasting our work and Hechinger et al. (2011) is particularly interesting because the involved trematodes belong to the same genus, and there are notable differences. First, there was considerable overlap in dimensions between the two redial types in Himasthla elongata from Aarhus, which was unparalleled by Himasthla sp. B. Second, in contrast to the larger reproductive morphs, defending rediae of Himasthla sp. B possessed collar and posterior locomotor appendages. In $H$. elongata both redial types expressed these morphological structures, albeit they are less visible on the cercariae-filled and hence swollen reproductive morph. Third, Himasthla sp. B rediae specialized for defence were disproportionately represented in the front part of the host, i.e. where new competing trematode infections are most likely to emerge (mantle, middle and hind-part: $\sim 99,55$ and $35 \%)$. Such a within-host spatial pattern was less pronounced in H. elongata (mantle, front and hind part: $\sim 99,16$ and $11 \%$; Knebel data). Fourth, the mean proportion of defending Himasthla sp. B rediae across colonies was $44 \%$, whereas this figure was well below $20 \%$ in $H$. elongata. Based upon 95\% confidence limits calculated for both Himasthla sp. B and $H$. elongata (data not shown), this difference between species is statistically significant. Finally, defending Himasthla sp. B rediae attack heterospecifics more than 20 times more often than reproductive rediae, while in $H$. elongata the non-reproductive rediae attack only 2-3 times more frequently than their reproductive counterparts. The magnitude of some of the discrepancies between Himasthla sp. B and $H$. elongata can be ascribed to the two studies' different methodology. In particular, Hechinger et al. (2011) separated the two redial types according to their dimensions, whereas we did so according to their reproductive state. Thus, the two trematode species may not differ as much as the two studies seem to indicate regarding overall relative abundance of the two identified redial morphs. Nevertheless, the reproductive morph of $H$. elongata possesses collar and well-defined posterior appendages, which appear to be absent in reproductive Himasthla sp. B. Further, in the directly 
comparable experiments on antagonistic behaviour, the defending redial morph of Himasthla sp. B was considerably more aggressive towards heterospecifics than defending $H$. elongata. Hence, under the assumption of adaptive division of labour in both parasite species, the Himasthla sp. B castes appear more specialized than those of $H$. elongata.

This scenario supports the expectations outlined in the introduction that $H$. elongata should be less specialized for defence of the colony because the ecological factors necessary for the evolution of castes in trematode parasites suggested by Hechinger et al. (2011) differ between the two species. First, the average prevalence of trematode infections in Littorina littorea across 35 studies worldwide is $9.7 \%$ and the trematode communities of $L$. littorea are on average composed of 3.3 species (six in total) whereas, in comparison, the average infection prevalence of C. californica is $27.3 \%$ (seven studies) and the trematode communities comprise 12.7 species on average (17 in total) (Werding, 1969; Sousa 1993; Kuris 1990; Poulin \& Mouritsen, 2003). This suggests that interspecific competition is considerably stronger in trematode communities of $C$. californica than in $L$. littorea. Second, L. littorea has a life expectancy of 4-10 yr, while $C$. californica has a life expectancy of 8-10 yr (Hyman, 1967; Sousa, 1983). The somewhat greater longevity of C. californica increases the possibility of interactions between infecting parasite species and makes the possible returns from future reproduction by the trematode higher.

Adopting a more narrow definition of division of labour, in which the two redial types need to be irreversibly distinct behavioural/morphological groups (e.g. Crespi \& Yanega, 1995), it is questionable whether a division of labour scenario can be retained in the case of $H$. elongata, as this aspect has not yet been investigated. In fact, the defending non-reproductive rediae could simply be fast-growing juveniles with a higher demand for nutrition during their development into reproductive rediae. Hechinger et al. (2011), Leung \& Poulin (2011) and Miura (2012) provide some lines of evidence suggesting that the main defending caste in these systems are indeed temporally stable (see also Lloyd \& Poulin, 2012). However, we find that this issue deserves additional attention across the so-far studied trematode-systems because unequivocal evidence of irreversible caste formation will be the undisputable proof of evolution of division of labour in trematoda. Although a direct comparison of our two samples (Aarhus and Knebel) is unwise, as they differ both spatially and temporally, the much smaller and entirely nonreproducing rediae found in the autumn sample (Knebel, Figure $3 \mathrm{~B}$ ) could be interpreted as a new redial generation that during the winter grows into a significantly larger and partly reproducing group of rediae in spring (Aarhus sample, Figure $3 \mathrm{~A}$ ). The observation of dead rediae in the mantle region supports this view as it suggests a certain level of turn-over among reproductive specimens. Moreover, a pilot study has shown that non-reproductive rediae of $H$. elongata do not attack and eat heterospecific Renicola roscovita sporocysts more willingly than they eat visceral tissue from their own snail host when given a choice (K.N. Mouritsen, unpublished data). This is not to be expected if nonreproductive rediae were adapted for the single purpose of defending the colony against invaders. Perhaps the role of small non-reproductive rediae in defending the colony is merely a matter of probability of meeting an invading competitor by virtue of their smaller size and therefore greater activity and mobility. The experimental demonstration by Lloyd \& Poulin (2012) that the in vitro cercarial production of reproductive Philopthalmus sp. rediae is elevated in the presence of non-reproducing morphs, and in the absence of heterospecific competitors, suggest that the role of the small non-reproducing colony members is not yet fully understood.

\section{ACKNDWLEDGEMENTS}

We wish to thank Morten Rud, Susanne Pedersen, Susanne Vase Petersen and Frej Juhl Halvorsen for work and assistance in the laboratory during the investigation.

\section{REFERENCES}

Aoki S. (1977) Colophina clematis (Homoptera, Pemphigidae), an aphid species with 'soldiers'. Kontyu 45, 276-282.

Bourke A.F.G. (2011) The validity and value of inclusive fitness theory. Proceedings of the Royal Society of London, B 278, 3313-3320.

Crespi B.J. (1994) Three conditions for the evolution of eusociality-are they sufficient? Insectes Sociaux 41, 395-400.

Crespi B.J. and Yanega D. (1995) The definition of eusociality. Behavioural Ecology 6, 109-115.

Esteban J.G. and Muñoz-Antoli (2009) Echinostomes: systematics and life cycles. In Fried B. and Toledo R. (eds) The biology of echinostomes. Berlin: Springer, pp. 1-33.

Galaktionov K.V. and Dobrovolskij A.A. (2003) The biology and evolution of trematodes. Dordrecht: Kluwer Academic.

Hamilton W.D. (1964) Genetical evolution of social behaviour. I and II. Journal of Theoretical Biology 7, 1-52.

Hechinger R.F., Wood A.C. and Kuris A.M. (2011) Social organization in a flatworm: trematode parasites form soldier and reproductive castes. Proceedings of the Royal Society of London, B 278, 656-665.

Hughes W.O.H., Oldroyd B.P., Beekman M. and Ratnieks F.L.W. (2008) Ancestral monogamy shows kin selection is key to the evolution of eusociality. Science 320, 1213-1216.

Hyman I.H. (1967) The invertebrates: volume VI, mollusca I. New York: McGraw-Hill.

Kuris A.M. (1990) Guild structure of larval trematodes in molluscan hosts: prevalence, dominance and significance of competition. In Esch G.W., Bush A.O. and Aho J.M. (eds) Parasite communities: patterns and processes. London: Chapmann and Hall, pp. 69-100.

Lauckner G. (1980) Diseases of mollusca: gastropoda. In Kinne O. (ed.) Diseases of marine animals, Volume 1. Hamburg: Biologische Anstalt Helgoland, pp. 311-424.

Lauckner G. (1983) Diseases of mollusca: bivalvia. In Kinne O. (ed.) Diseases of marine animals, Volume 2. Hamburg: Biologische Anstalt Helgoland, pp. 477-962.

Leung T.L.F. and Poulin R. (2012) Small worms, big appetites: ratios of different functional morphs in relation to interspecific competition in trematode parasites. International Journal for Parasitology 41 , $1063-1068$.

Lloyd M.M. and Poulin R. (2012) Fitness benefits of a division of labour in parasitic trematode colonies with and without competition. International Journal for Parasitology 42, 939-946.

Miura O. (2012) Social organization and caste formation in three additional parasitic flatworm species. Marine Ecology Progress Series $465,119-127$ 
Nowak M.A., Tarnita C.E. and Wilson E.O. (2010) The evolution of eusociality. Nature 466, 1057-1062.

Poulin R. and Mouritsen K.N. (2003) Large-scale determinants of trematode infections in intertidal gastropods. Marine Ecology Progress Series $254,187-198$.

Sousa W.P. (1983) Host life history and the effect of parasitic castration on growth: a field study of Cerithidea californica Haldeman (Gastropoda: Prosobranchia) and its trematode parasites. Journal of Experimental Marine Biology and Ecology 73, 273-296.

Sousa W. (1993) Interspecifik antagonism and species coexistence in a diverse guild of larval trematode parasites. Ecological Monographs $63,103-128$.

Stunkard H.W. (1938) The morphology and life cycle of the trematode Himasthla quissetensis (Miller and Northup, 1926). Biological Bulletin. Marine Biological Laboratory, Woods Hole 75, 145-164.
Stunkard H.W. (1966) The morphology and life history of the digenetic trematode Himasthla littorinae sp. (Echinostomatidae). Journal of Parasitology 52, 367-372.

Werding B. (1969) Morphologie, entwicklung und ökologie digener trematoden-larven der strandschnecke Littorina littorea. Marine Biology 3, 306-333.

and

Wilson E.O. (1971) The insect societies. Cambridge, MA: Belknap Press of Harvard University Press.

\section{Correspondence should be addressed to:}

K.N. Mouritsen

Department of Bioscience, Aarhus University, Ole Worms Allé 1, 8000 Aarhus C, Denmark email: kim.mouritsen@biology.au.dk 